\title{
The protective effect of L-tryptophan versus alpha lipoic acid against L-arginine-induced experimental acute pancreatitis in albino rats
}

\author{
Lamia M. Farghaly* , Nagwan A. Sabak ** and Naglaa A. El-sherbeny*** \\ Departments of Histology*, Biochemistry**and Pharmacology.*** \\ Faculty of Medicine, Suez Canal University.
}

\begin{abstract}
Aim of the study: This study was conducted to investigate the possible protective effects of L- treptophan "a precursor of melatonin" and alpha lipoic acid against L- arginine-induced experimental acute pancreatitis in albino rats.

Methods: Fourty adult male albino rats $(200-250 \mathrm{~g})$ were randomized into 4 groups $(\mathrm{n}=$ 10). Group I, the control group was given $0.9 \%$ saline intraperitoneally (i.p). Group II, was given $500 \mathrm{mg} / 100 \mathrm{~g} \mathrm{~L}$-arginine (i.p) as a single dose to induce acute pancreatitis. Group III: was given $250 \mathrm{mg} / \mathrm{kg}$ L-tryptophan (i.p) $30 \mathrm{~min}$ prior to L- arginine injection. Group IV: was given $50 \mathrm{mg} / \mathrm{kg}$ alpha lipioc acid(i.p) $30 \mathrm{~min}$ prior to L-arginine. Before scarifice, blood samples were obtained from all groups to assay serum amylase and interleukin 6. Animals were sacrificed after 6 hours. For the histopathological study, pancreatic tissue was prepared for histological (H\&E, PAS) histochemical ( Tween stain for lipases) and immunohistochemical ( Bax stain for apoptosis) techniques. Both qualitative and quantitative analyses were done to assess the degree of acinar cells affection

Results: It was revealed that serum amylase and interleukin 6 in group II rose rapidly. Microscopically, severe acinar cells degeneration, interstitial edema, diffuse bleeding and inflammatory infiltration were demonstrated. These changes were markedly improved with the administration of both L- tryptophan and alpha lipoic acid.

Conclusion: It was concluded that both L- tryptophan \& alpha lipoic acid reduced the effects of L-arginine-induced acute pancreatitis with better protection achieved by L-tryptophan administration.
\end{abstract}

\section{Introduction:}

Acute pancreatitis ( AP) is a clinical entity that is believed to have intracellular activation of digestive enzymes and autodigestion of the pancreas as its central patho-physiologic cause. This non-infectious destruction of pancreatic parenchyma quickly induces an inflammatory reaction at the site of injury ( Park et al ., 2005)

Despite medical treatment, the lethality of severe acute pancreatitis is still high (20-30\%) ( Peter et al ., 2004)

Histologically, acute pancreatitis is characterized by interstitial edema, vacuolization, inflammation and acinar cell necrosis ( Baron and Morgan, 1999).

The diagnosis of acute pancreatitis is usually based on pancreatic edema index (pancreatic weight/ body weight), pancreatic serum enzymes (e.g.pancreatic amylase, lipase, immunoreactive trypsin or elastase) at animal models ( Smotkin and Tenner, 2002).

Therefore, it is advised to find good animal models to characterize the events of this severe disease. Mizinuma et al. (1984) were the first who studied the type of experimental necrotizing pancreatitis by intraperitoneal administration of a high single dose $(500 \mathrm{mg} / 100 \mathrm{~g})$ of L-arginine in albino rats. They demonstrated that $70-80 \%$ of acinar cells were necrotized without any morphological change in the islets of Langerhans ( Peter et al ., 2004).

It was shown in experimental models that several anti-inflammatory and antioxidant compounds, inspite of their diverse structure, were all capable of reducing the severity of many substances 
such as,caerulein, sodium taurocholate and L-arginine-induced experimental acute pancreatitis( Beglinger, 1999).

Some studies suggest that L-tryptophan a precursor of melatonin, which is considered potent antioxidant, can protect cells and tissues by attacking oxidants, blocking oxidant production, modulating lipoprotein metabolism and inhibiting lipid peroxidation ( Leja et al ., 2004).

$\alpha$ - lipoic acid (ALA) is a thiol antioxidant compound with demonstrated direct free-radical scavenging properties (Atmaca, 2004).It is called a universal antioxidant because it is soluble in both water and lipid based tissue ( Packer et al., 1995).

Therefore, the aim of the present study was to clarify the protective effects of L-tryptophan versus $\alpha$-lipoic acid against L-arginine-induced experimental acute pancreatitis in albino rats.

\section{Material and Methods:}

\section{A) Animals}

This study was carried out on 40 adult male albino rats, each weighing 200-250g. They were housed 10 per cage and allowed for acclimatization before the start of the work for one week. Animals had free access to food and water, but they were deprived of food 12 hours prior to the experiment. They were kept under normal room condition of temperature, humidity and normal light cycle.

\section{(B) Drugs}

L-arginine was obtained from Winlab Chemical Company as 100 grams pure white powder, and was given as $500 \mathrm{mg} /$ $100 \mathrm{~g}$ (i.p) as a single dose, dissolved in $0.9 \%$ saline to induce acute pancreatitis (Peter et al ., 2004). L-tryptophan was obtained from Sigma, 25grams pure slightly yellowish powder, and was given as $250 \mathrm{mg} / \mathrm{kg}$ ( i.p) as a single dose 30 minutes prior to L-arginine. It was dissolved in a drop of $0,1 \mathrm{~N} \mathrm{HCl}$ and then in $0,9 \%$ saline ( Leja et al ., 2004).

Alpha lipoic acid ( Thioatacid) was obtained from ( Eva- Pharmaceuticals) as $300 \mathrm{mg}$ tablets. Tablets were chewed and given in a dose of $50 \mathrm{mg} / \mathrm{kg}, 30$ minutes prior to L-arginine

( Park et al., 2005)

\section{( C) Study design:}

The animals were randomly divided into 4 groups (10 animals each) as following:

GroupI: considered as control, received $0.5 \mathrm{ml}$ saline (i.p).

GroupII: received L-arginine $(500 \mathrm{mg} /$ $100 \mathrm{~g}$ ) (i.p) as a single dose.

GroupIII: received L-tryptophan (250 $\mathrm{mg} / \mathrm{kg}$ ) (i.p) prior to L-arginine injection.

GroupIV: received $\alpha$-lipoic acid $(50 \mathrm{mg} / \mathrm{kg}$ ) (i.p) prior to L-arginine injection.

\section{(D) Biochemical data:}

At the end of the experiment, blood samples were obtained from retro-orbital venous plexus by capillary tubes without anaesthesia into clear centrifugation tubes. Serum was isolated by centrifugation to estimate amylase enzyme and interleukin 6. Kinetic determination of $\alpha$ - amylase activity according to the methods obtained by Winn- Deen et al. ( 1988).IL-6 was estimated by using chemiluminescent immunoassay procedure by IMMUIITE/ DPC. The principle of technique according to the method obtained by Hirano et al . (1990).

\section{(E) Histological techniques}

Pancreatic tissue of each rat was dissected out, fixed immediately in $10 \%$ neutral buffered formalin and processed to prepare $5 \mu \mathrm{m}$ thick paraffin sections. For histological techniques, sections were stained with H\&E and periodic acid Schiff (PAS) ( Bancroft \& Steven 1990)

For histochemical technique, sections were stained with Tween stain for demonstration of lipases ( Drury and Wallington, 1980).

For immunohistochemical technique, localization of pancreatic Bax was done on $4 \mu \mathrm{m}$ paraffin embedded tissues using a rabbit anti- human polyclonal antibody and a goat anti-rabbit secondary antibody (Gomez et al., 2001). 


\section{Lamia M. Farghaly et al}

H\&E stained sections were used for quantitative analysis to assess the degree of acute pancreatitis.

According to Jaworek et al. (2001) the histological grading of (edema, cellular infiltration, necrosis and vacuolization ) was made using a scale ranging from 0 to 3 in which $0=$ none and $3=$ severe. For all morphological studies of pancreatic acinar damage, 10 high power fields ( $\mathrm{x} 400$ ) were assessed per section and 3 sections were examined from each animal.

Quantitative measurements were carried out using the image analyzer (Super eye- Heidi soft) to measure:

1- The optical density of the magenta colour of basement membranes in the PAS stained sections.

2-The optical density of Bax immunostaining in pancreatic acinar cells cytoplasm.

\section{F) Statistical analysis:}

The data were analyzed using SPSS statistical soft-ware. Comparison of the above mentioned, biochemical and histological parameters among different groups using student's $t$-test for each measure-ment in each group. $\mathrm{P}<0.05$ was considered statistically significant (Armitage and Berry, 1994).

\section{Results}

\section{Biochemical analysis results:}

Effect of intraperitoneal injection of L-arginine $500 \mathrm{mg} / 100 \mathrm{~g}$ as a single dose, on some metabolic parameters ( serum amylase and interleukin-6). The results of this study showed that serum amylase level was increased significantly $(\mathrm{P}<0.01)$ from $320.83 \mathrm{U} / 1$ in the control group to 990.98 $\mathrm{U} / 1$ in the L-arginine group. The same significant increase was also observed regarding the mean values of serum IL-6, which increased from $65.13 \mathrm{pg} / \mathrm{ml}$ in the control group to $301.61 \mathrm{pg} / \mathrm{mL}$ respectively in the L-arginine group (Table 1). Effect of intraperitoneal administration of L-tryptophan and alpha-lipoic acid on the same metabolic parameters.

Biochemical results showed that the mean blood amylase level was decreased significantly from $990.98 \mathrm{U} / \mathrm{l}$ in the Larginine group to $798.22 \mathrm{U} / \mathrm{l}$ and 817.11 $\mathrm{U} / 1$ in groups that received LT and ALA. Regarding IL-6 serum level, there was a significant decrease $(\mathrm{P}<0.05)$ from a mean value of $301.61 \mathrm{pg} / \mathrm{mL}$ in the $\mathrm{L} \mathrm{A}$ group to a mean values $224.75 \mathrm{pg} / \mathrm{mL}$ and $236.88 \mathrm{pg} / \mathrm{mL}$ in the LT and ALA groups respectively ( Table 1 ).

\section{Histological results}

Group I( Control group):

Light microscopic examination of $H \& E$ stained sections of the rat pancreas of this group revealed that the pancreatic acini appeared deeply stained, rounded in shape in cross section. They were lined with pyramidal cells arranged around a narrow central lumen. The acinar cells were seen to have basal rounded vesicular nuclei. The islets of Langerhans appeared as non-capsulated pale pink oval or rounded areas inside the pancreatic lobules. They appeared to be formed of groups of cells arranged in irregular branching and anastomosing cords separated by blood capillaries ( Fig. 1).

PAS stained sections showed that the basement membranes of pancreatic acini, prominent blood vessels and islets capillaries were PAS +ve. No PAS +ve material was seen within the islets or separating them from the exocrine part of the pancreas ( Fig. 2). The mean optical density of PAS positive material in the basement membrane of control group was $0.38 \pm 0.08$ (Table 3). Using Tween stain, a strong lipase activity was demonstrated in the cytoplasm of pancreatic acini. Fine brownish granules indicating the enzymatic activity were homogenously distributed in the cytoplasm (Fig. 3). Bax immunostaining showed negative expression of the apoptosis in the cells of the pancreatic acini ( Fig. 4). The mean optical density of Bax immunostaining in acinar cells cytoplasm was $0.01 \pm 0.12$ ( Table 3 ).

Group II ( L-arginine group):

Intraperitoneal administration of $\mathrm{L}$ arginine $(500 \mathrm{mg} / 100 \mathrm{~g})$ produced typical pancreatic lesions in all tested rats. Macroscopically, the pancreas was grossly 
swollen and enlarged with visible foci of hemorrhage. The peritoneal fluid was present in all animals. H\&E stained sections of the rat pancreas of this group revealed that most pancreatic acini showed excessive distortion in the form of marked degenerative and necrotic changes in acinar cells which appeared to be separated by wide intercellular spaces. There was massive interstitial edema, accompanied by vascular congestion, cellular infiltration and acinar cells necrosis. The necrotic changes occurred in $(2.9 \pm 0.1)$ of the pancreatic acini. They were in the form of nuclear pyknosis, karyorrhexis and karyolysis.

$(2.5 \pm 0.2)$ of the pancreatic acini showed vacuolization of their cytoplasm (Table2). Congestion of blood vessels, interstitial edema $(2.7 \pm 0.1)$ and mononuclear cellular infiltration $(2.6 \pm 0.3)$ were more prominent in this group (Fig. 5) and ( Table 2). PAS stained sections showed a decrease in the basement membranes in most pancreatic acini ( Fig. 6). The mean optical density of PAS positive basement membrane of acini was $0.14 \pm 0.02$ which was statistically significantly decreased compared to control (Table 3). Sections stained with Tween stain revealed that most acinar cells apparently showed weak lipase activity compared to control ( Fig. 7). A marked increase of Bax immunostaining was observed in most acinar cells. Their nuclei appeared dark brown, condensed and fragmented ( Fig. 8). The mean optical density of Bax immunostaining in acinar cells cytoplasm in this group was $41.75 \pm 5.48$ which was statistically significantly increased compared to control ( Table 3 ).

\section{Group III ( L-tryptophan+ L-arginine group):}

H\&E stained sections of this group revealed that all the previous histopathological changes were significantly less pronounced. Edema was markedly diminished, infiltration was reduced, necrosis and vacuolization were significantly decreased (Table2). Some acinar cells appeared necrotic ( $2.2 \pm 0.2)$, while others exhibited vacuolization ( $1.9 \pm 0.6$ ) ( Table 2). Slight edematous fluid $(1.7 \pm 0.5)$ within and around dilated pancreatic duct and extravasated red blood cells were also observed ( Fig. 9).

PAS stained sections showed positive basement membranes material nearly similar to control ( Fig. 10). The mean optical density of PAS positive basement membranes was $0.36 \pm 0.06$ which was statistically significant compared to Larginine group ( Table 3). Sections stained with Tween stain revealed that some pancreatic acini regained the enzymatic activity for lipases (Fig.11). Immunostained sections showed mild expression of Bax immunostaining. The cells of the majority of the pancreatic acini revealed faint to mild immunostaining for Bax mainly in the nuclei ( Fig. 12). The mean optical density of immunostaining in acinar cells cytoplasm in this group was $13.37 \pm 1.83$ which was statistically significantly decreased compared to L-arginine group ( Table 3 ).

\section{Group IV ( Alph- lipoic acid + L-arginine group):}

In rats pretreated with ALA prior to L-arginine administration, there was significant improvement of pancreatic integrity and attenuation of most morphological changes produced by L-arginine. Some protection was achieved. H\&E stained sections showed hemorrhage and interstitial edema between some distorted acini . The edema was mild ( $1.9 \pm 0.4$ ), some of the acinar cells showed pyknotic nuclei $(2.3 \pm 0.4)$, and others appeared vacuolated $(2.1 \pm 0.3)$ (Table 2). There was mild cellular infiltration inbetween dilated intralobular pancreatic duct which contained fibrinous exudates and dilated congested blood vessel (Fig.13) (Table 2).

PAS stained sections showed moderate decrease of PAS +ve basement membrane of pancreatic acini, while that of the blood vessels were not affected ( Fig.14). The mean optical density of PAS positive basement membranes was $0.29 \pm 0.04$ which was statistically significant $(\mathrm{P}<0.05)$ compared to L-arginine and L-tryptophan groups ( Table 3). Sections stained with Tween stain revealed moderated decrease of lipase activity in many acini (Fig.15). Immunostained sect- 
ions showed moderate reaction of Bax immunostaining in many pancreatic acini ( Fig.16). The mean optical density of Bax immunostaining in this group was $15.48 \pm 2.76$ which was statistically significant compared to L-arginine and Ltryptophan groups (Table3).

Table ( 1 ) shows some metabolic parameters in the different experimental groups compared to control $(n=40)$

\begin{tabular}{|l|c|c|}
\hline Groups & Amylase (U/l) & $\mathrm{IL}-6(\mathrm{Pg} / \mathrm{ml})$ \\
\hline Control & $320.83 \pm 180.32$ & $65.13 \pm 13.91$ \\
& & $* 301.61 \pm 28.60$ \\
\hline L-arginine & $* 990.98 \pm 286.99$ & 3.418 \\
t-value & 9.876 & $* * 224.75 \pm 20.85$ \\
\hline Ltryptophan+arginine & $* * 798.22 \pm 185.23$ & 2.013 \\
t-value & 6.915 & $* * 236.88 \pm 21.26$ \\
\hline ALA+L-arginine & $* * 817.11 \pm 188.75 \quad 8.012$ & 2.987 \\
t-value & & \\
\hline
\end{tabular}

*Highly significant $(\mathrm{P}<0.01$ compared to the control group).

**Significant $(\mathrm{P}<0.05$ compared to the $\mathrm{L}$-arginine group).

Table ( 2): shows the frequency distribution of the histopathological changes in the pancreatic acini in the different experimental groups $(n=40)$

\begin{tabular}{|l|c|c|c|c|}
\hline Group & $\begin{array}{c}\text { Edema } \\
(0-3)\end{array}$ & $\begin{array}{c}\text { Infiltration } \\
(0-3)\end{array}$ & $\begin{array}{c}\text { Necrosis } \\
(0-3)\end{array}$ & $\begin{array}{c}\text { Vacuolization 0- } \\
0-(3)\end{array}$ \\
\hline Control & 0 & 0 & 0.1 & 0 \\
\hline L-arginine & $* 2.7 \pm 0.1$ & $2.6 \pm 0.3^{*}$ & $2.9 \pm 0.1^{*}$ & $* 2.5 \pm 0.2$ \\
\hline $\begin{array}{c}\text { tryptophan+L- } \\
\text { arginine }\end{array}$ & $* * 1.7 \pm 0.5$ & $* * 1.6 \pm 0.2$ & $* * 2.2 \pm 0.2$ & $1.9 \pm 0.6^{* *}$ \\
\hline ALA+L-arginine & $* * 1.9 \pm 0.4$ & $* * 1.8 \pm 0.3$ & $* * 2.3 \pm 0.4$ & $* * 2.1 \pm 0.3$ \\
\hline
\end{tabular}

*Highly significant $(\mathrm{P}<0.01$ compared to the control group $)$.

**Significant $(\mathrm{P}<0.05$ compared to the L-arginine group $)$.

Table ( 3 ): shows density (Area\%) of PAS and of Bax immunostaining in pancreatic acini in the different experimental $\operatorname{groups}(n=40)$

\begin{tabular}{|l|c|c|}
\hline Groups & $\begin{array}{c}\text { Mean optical density of PAS } \\
+ \text { ve reaction } \pm \text { SD }\end{array}$ & $\begin{array}{c}\text { Mean optical density of Bax } \\
\text { reaction } \pm \text { SD }\end{array}$ \\
\hline Control & $0.38 \pm 0.08$ & $0.01 \pm 0.02$ \\
\hline L-arginine & $* 0.14 \pm 0.02$ & $* 41.75 \pm 548$ \\
\hline Ltryptophan+L-argininel & $* * 0.36 \pm 0.06$ & $* * 13.37 \pm 1.83$ \\
\hline ALA+ L-arginine & $* * 0.29 \pm 0.04$ & $* * 15.48 \pm 2.76$ \\
\hline
\end{tabular}

*Highly significant $(\mathrm{P}<0.01$ compared to the control group).

**Significant ( $\mathrm{P}<0.05$ compared to the L-arginine group). 
The protective effect of L-tryptophan versus alpha.........

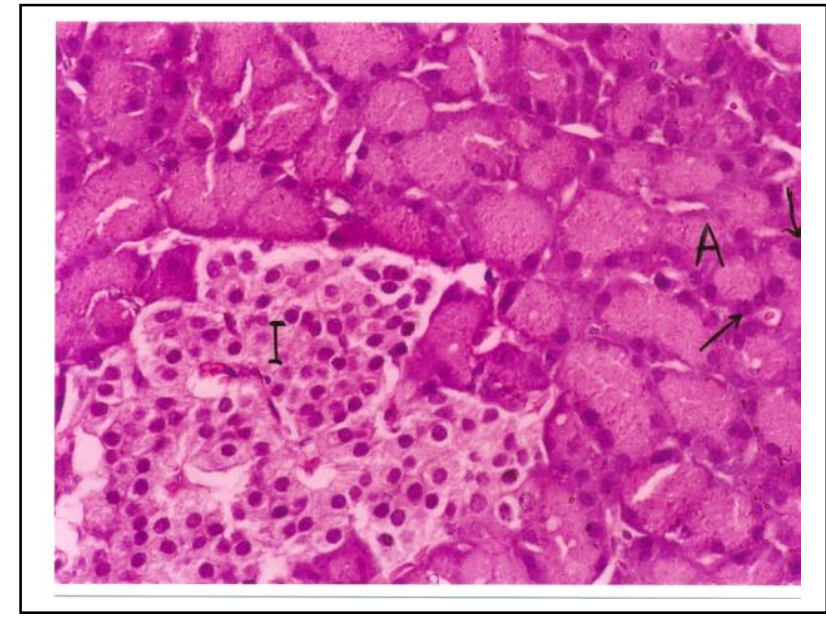

Fig 1- Section in the pancreas of a control rat showing islet of Langerhans (I) surrounded by deeply stained acini (A) having rounded basal nuclei $(\uparrow)$.

( H\&E- X 400 ).

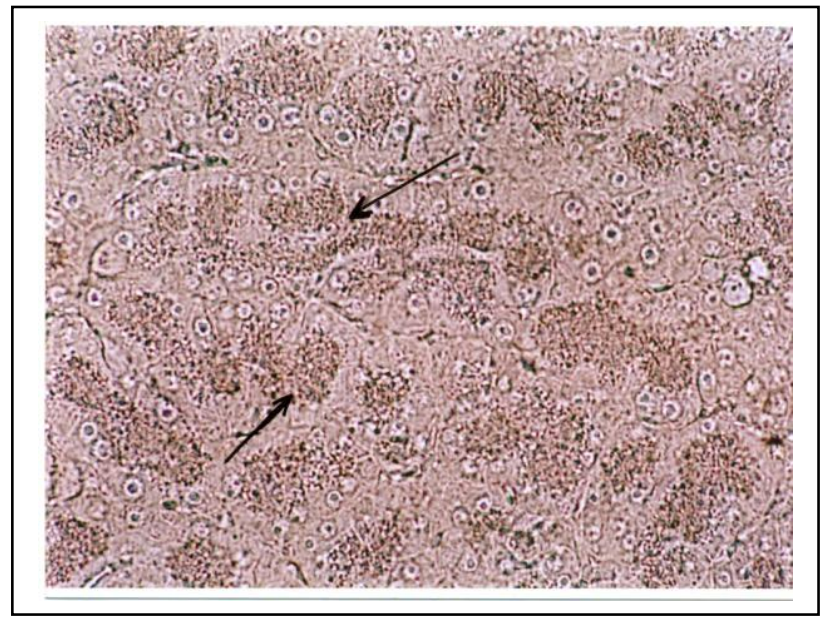

Fig 3- Section in the pancreas of a control rat showing densely packed pancreatic acini with fine brownish granules of lipase reaction $(\uparrow)$.

( Tween stain- X 400).

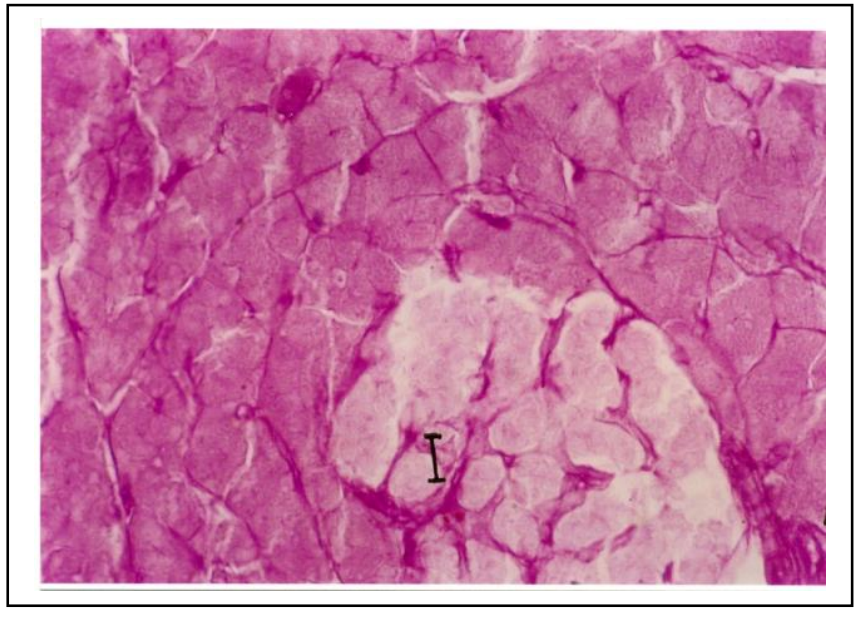

Fig 2- Section in the pancreas of a control rat showing PAS positive basement membranes of pancreatic acini, blood vessel $(\uparrow)$ and islet capillaries ( I ).

( PAS- X 400 ).

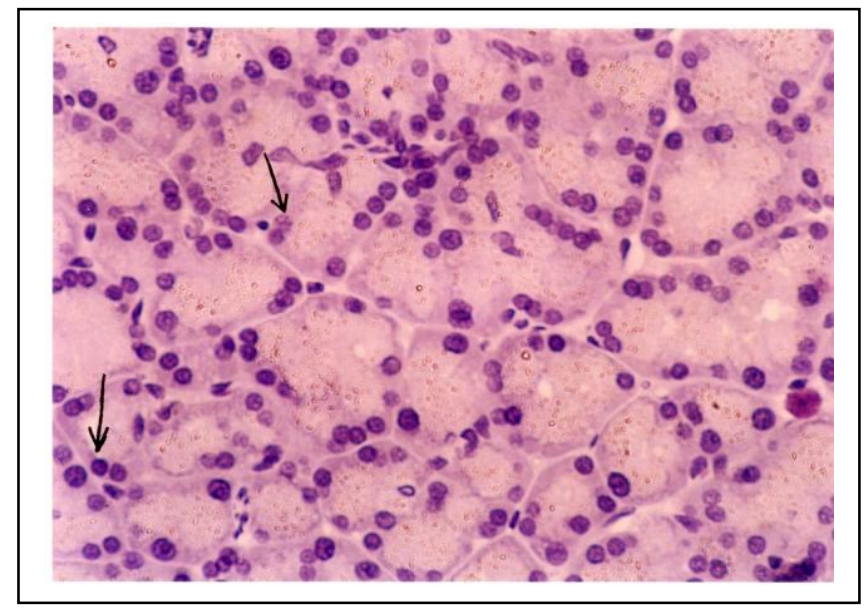

Fig 4- Section in the pancreas of a control rat showing negative immunostaining of Bax in cells of the pancreatic acini $(\uparrow)$.

( Bax immunostaining - X 400 ). 


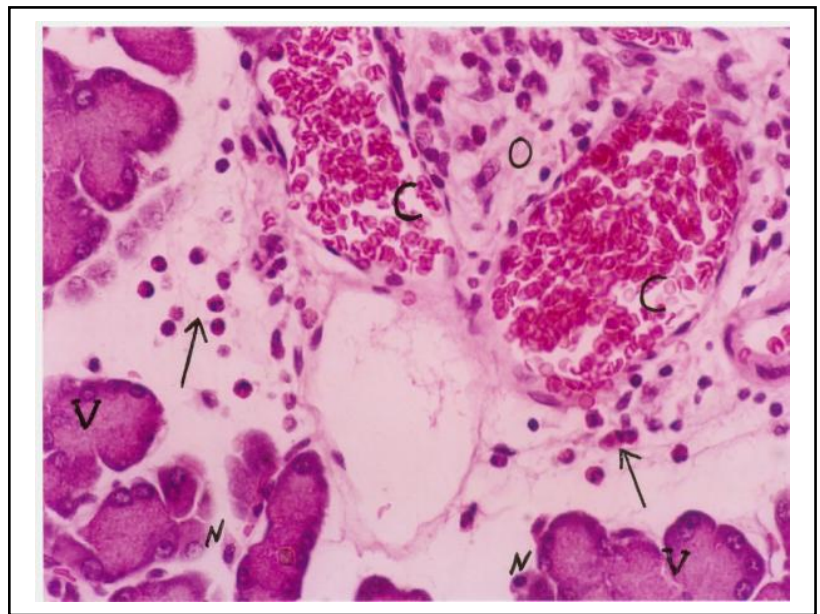

Fig 5- Section in the pancreas of a rat injected with L-arginine showing acinar cells necrosis ( $\mathbf{N}$ ) and vacuolization ( V), severe congestion of blood vessels $(\mathrm{C})$, accumulation of edematous fluid $(\mathrm{O})$ and cellular infiltration $(\uparrow)$.

( H\&E -X 400 ).

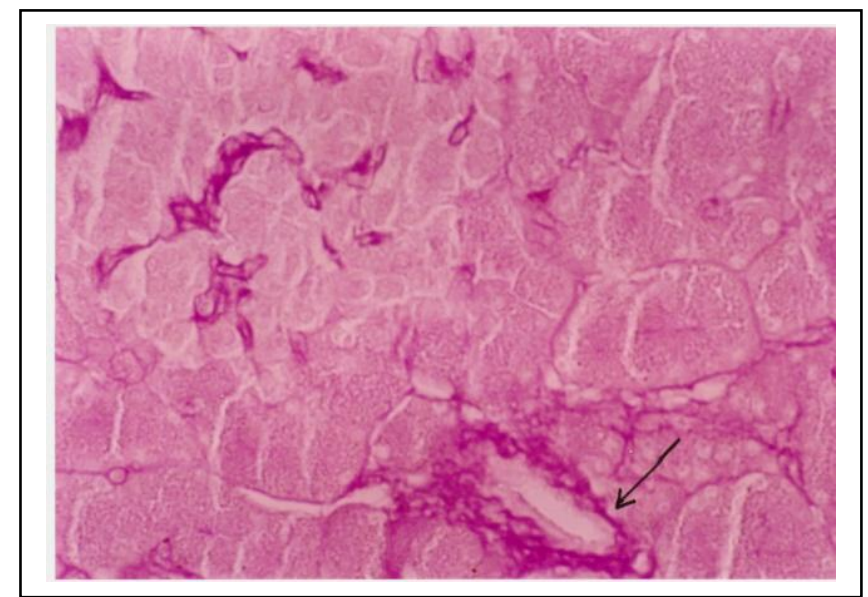

Fig 6- Section in the pancreas of a rat injected with L-arginine showing decrease of PAS positive basement membrane in most acini while that of the blood vessel are not affected $(\uparrow)$.

( PAS- X 400 ).

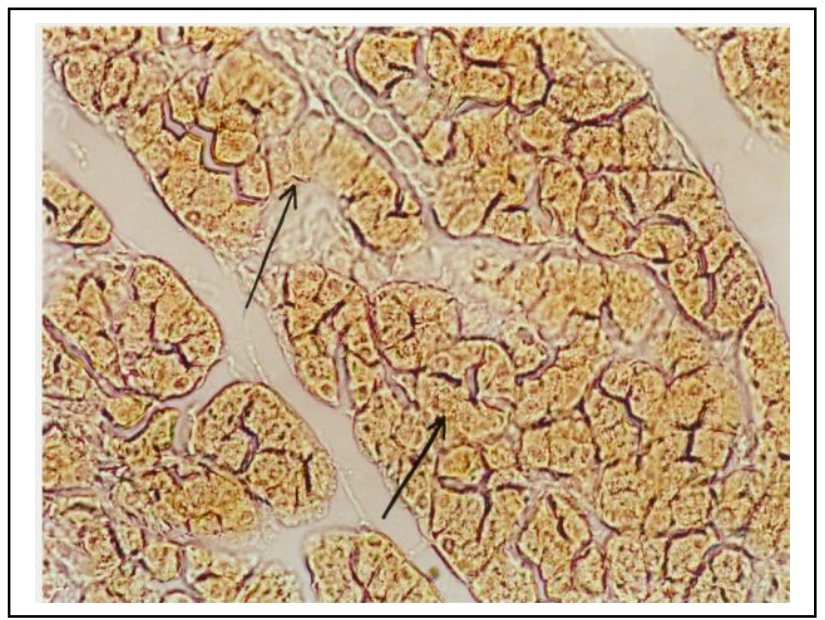

Fig 7- Section in the pancreas of a rat injected with L-arginine showing decreased lipase reaction in most acinar cells $(\uparrow)$. ( Tween stain -X 400 ).

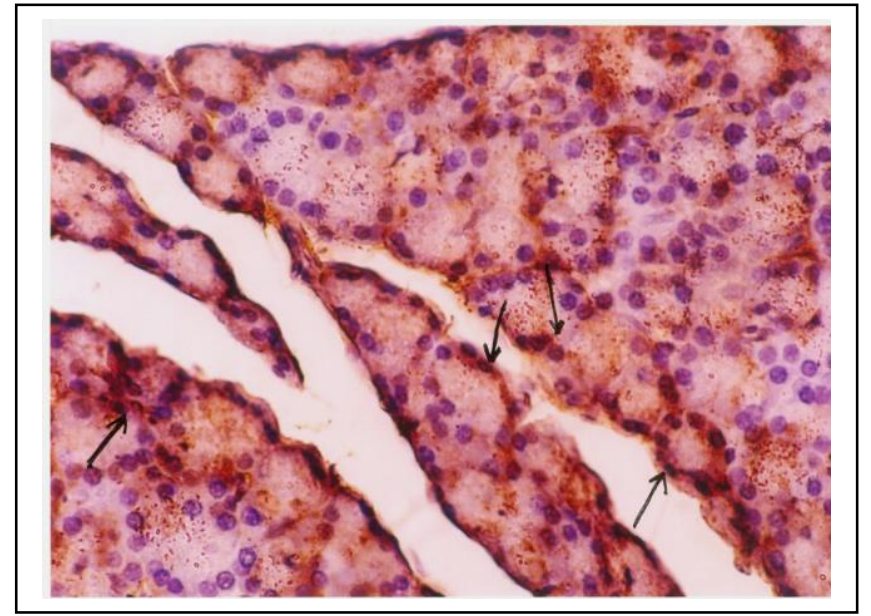

Fig 8- Section in the pancreas of a rat injected with $L$-arginine showing marked increase in Bax immunostaining in the acinar cells. The acinar cell nuclei appeared condensed, fragmented and dispersed in the condensed cytoplasm $(\uparrow)$.

( Bax immunostaining -X 400 ). 


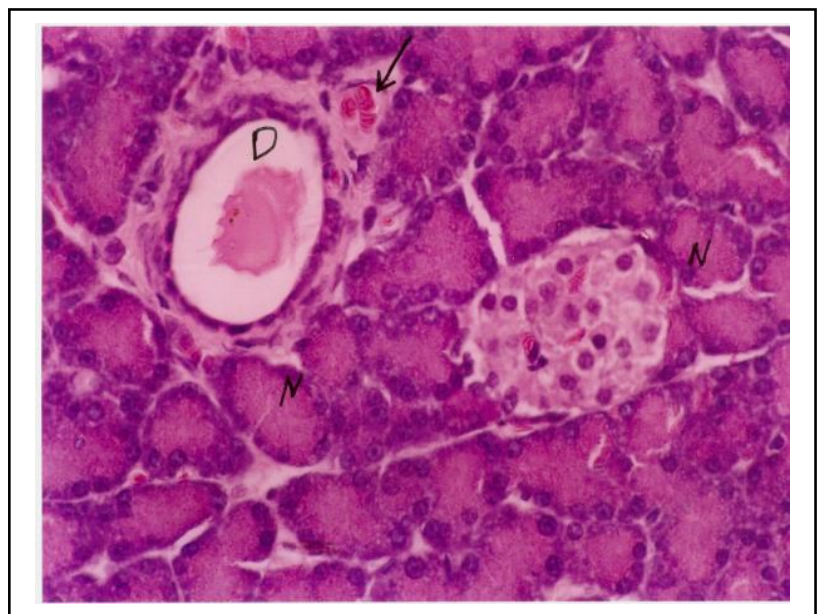

Fig 9- Section in the pancreas of a rat injected with L-tryptophan prior to $\mathbf{L}$-arginine showing some necrotic acinar nuclei (N), edematous fluid within and around dilated ducts (D) and some extravasated blood cells $(\uparrow)$.

( H\& E - X 400 ).

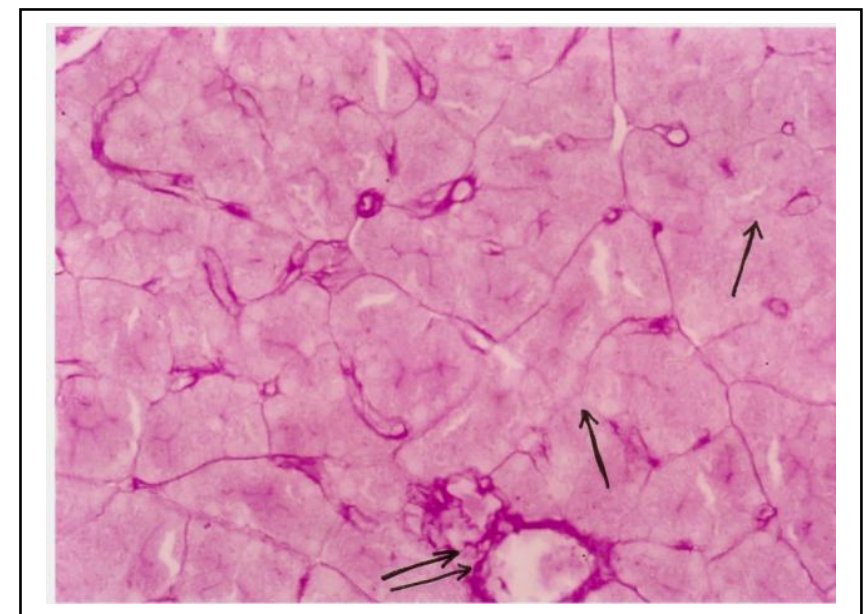

Fig 10- Section in the pancreas of a rat injected with L-tryptophan prior to $L$ arginine showing mild decrease of PAS positive basement membrane of some pancreatic acini $(\uparrow)$ while that of the blood vessels are not affected $(\uparrow \uparrow)$.

( PAS - X 400 ).

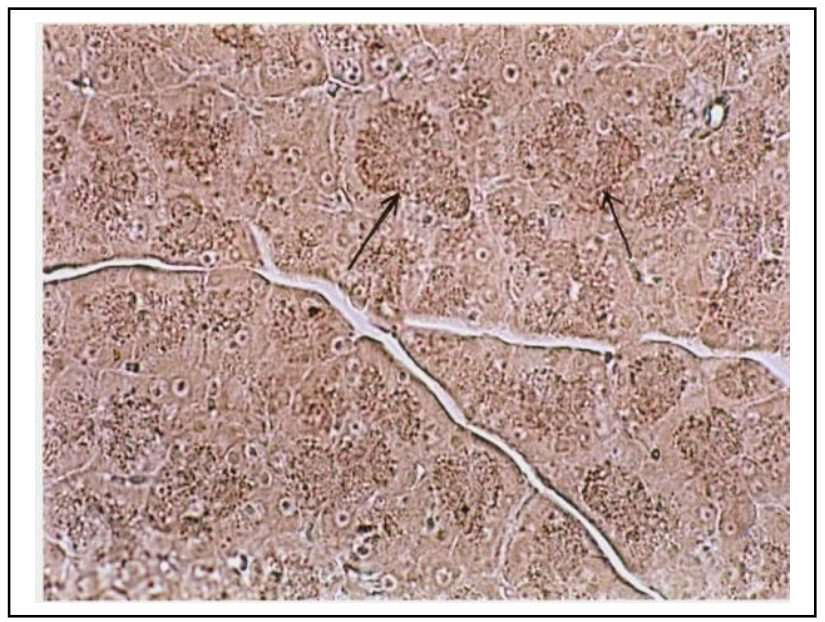

Fig 11- Section in the pancreas of a rat injected with $L$-tryptophan prior to $L$ arginine showing that, many pancreatic acini regained the enzymatic activity for lipases $(\uparrow)$.

( Tween stain- X 400 ).

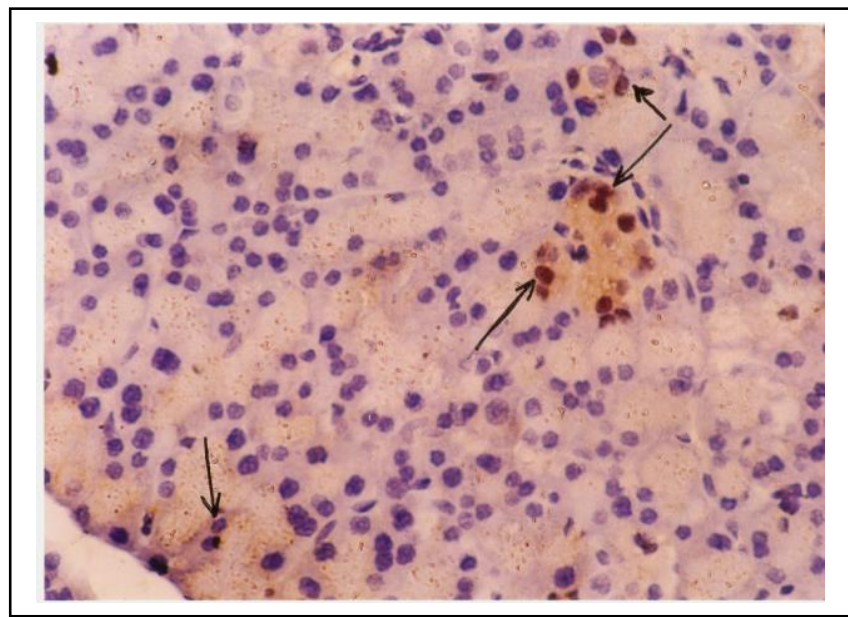

Fig 12- Section in the pancreas of a rat injected with L-tryptophan prior to L-arginine showing mild reaction of Bax immunostaining, some acinar cell nuclei appeared condensed and fragmented $(\uparrow)$.

( Bax immunostaining- X 400 ). 


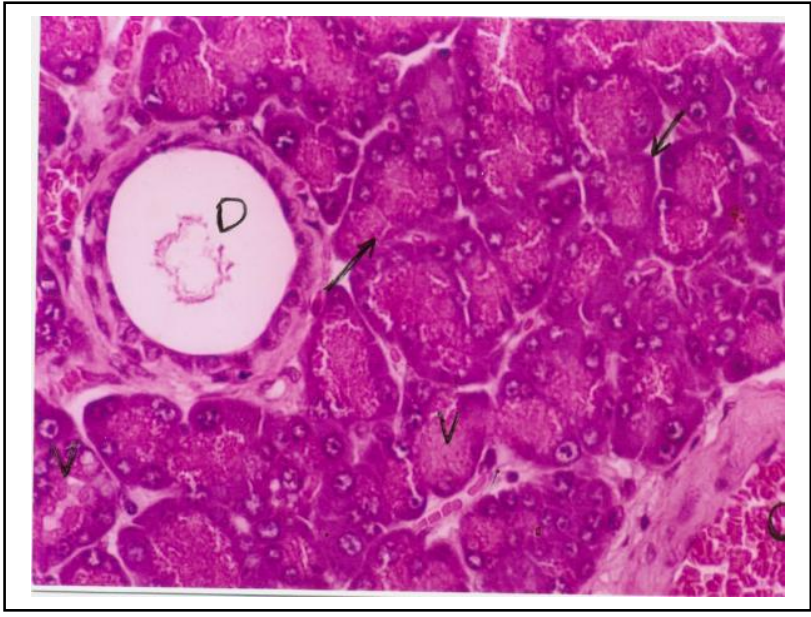

Fig 13- Section in the pancreas of a rat injected with ALA prior to L-arginine showing distorted acini full of zymogen granules, some of which showing loss of their nuclei $(\uparrow)$ and others showing vacuolization $(\mathrm{V})$. Dilated intralobular duct containing fibrinous exudates (D) and congested blood vessel $(C)$ are also seen.

( H \& E - X 400).

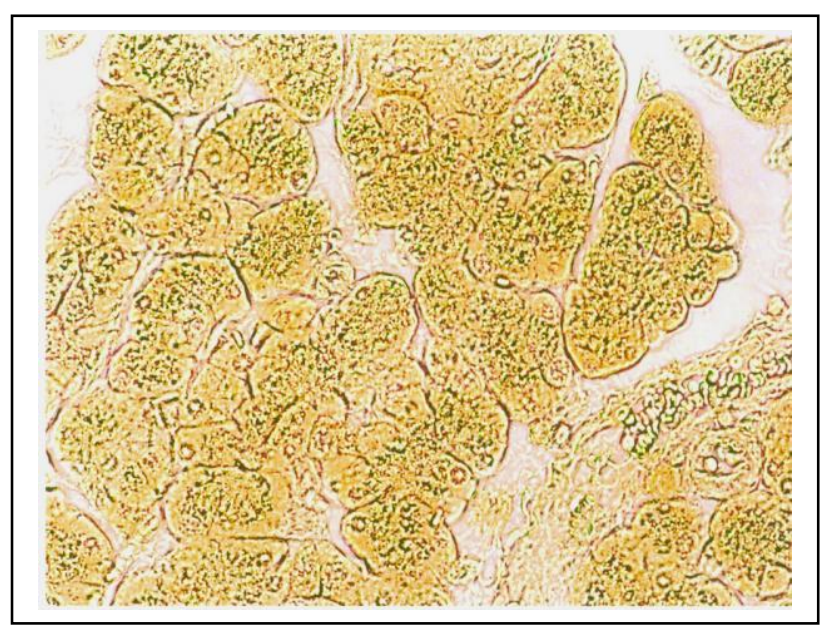

Fig 15- Section in the pancreas of a rat injected with ALA prior to L-arginine showing moderate decrease of lipase reaction.

( Tween stain - X 400 ).

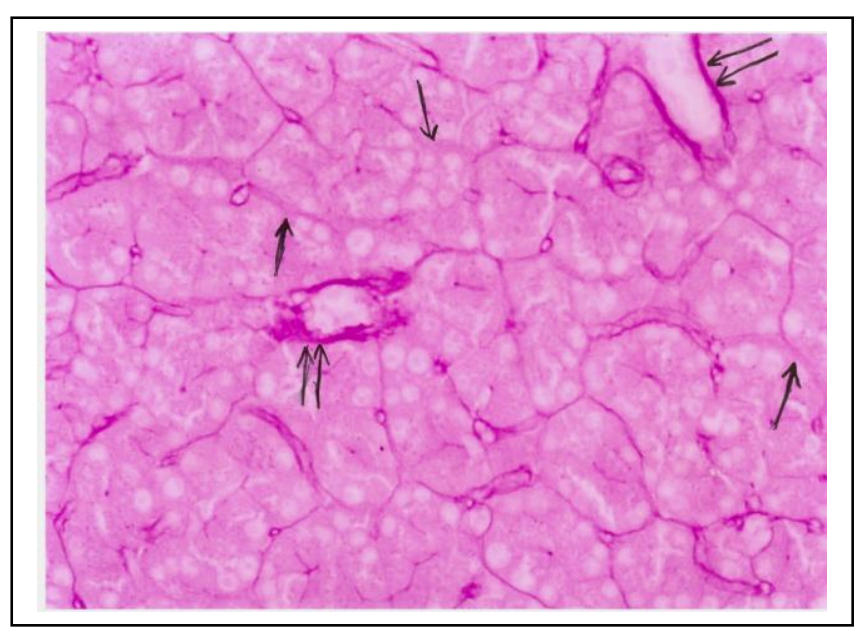

Fig 14- Section in the pancreas of a rat injected with ALA prior to L-arginine showing moderate decrease of PAS positive basement membrane of many acini $(\uparrow)$ while that of the blood vessels are not affected $(\uparrow \uparrow)$.

( PAS- X 400 ).

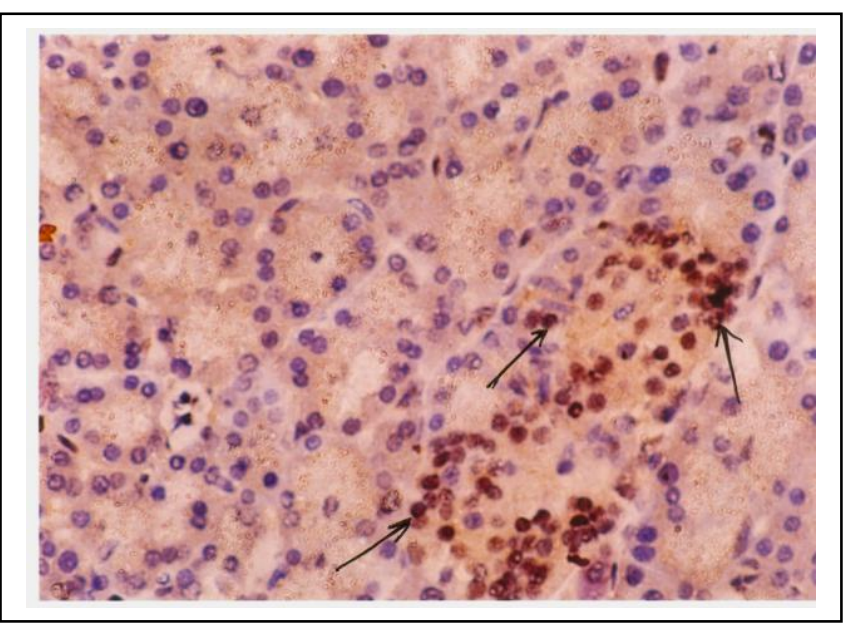

Fig 16- Section in the pancreas of a rat injected with ALA prior to $L$-arginine showing moderate reaction of Bax immunostaining, many acinar nuclei appeared dark brown, condensed and fragmented $(\uparrow)$.

( Bax immunostaining - X 400 ). 


\section{Discussion}

In man, acute pancreatitis ( AP) is a severe disease with significant morbidity and mortality ( Banks, 1993). In order to better understand the underlying cellular mechanisms of AP in humans, several experimental animal models of AP have been developed. These models include a choline-defficient and ethionine- supplemented diet, obstruction of the pancreatic duct by using sodium taurocholate, and infusion of supra-maximal doses of Larginine, cholecystokinin or its longer acting analogue "cerulein" ( Gomez et al ., 2001)

L-arginine induced pancreatitis results in many of the features of human pancreatitis, including elevated serum amylase , pancreatic edema, inflammation and acinar cell death ( Peter et al ., 2004). So the present work was designed to study the protective effect of the L-tryptophan versus alpha-lipoic acid against L-arginineinduced experimental acute pancreatitis in albino rats. The results of the present work revealed that when $\mathrm{L}$-arginine was given (i.p) in a single dose of $500 \mathrm{mg} / 100 \mathrm{~g} \mathrm{BW}$, it produced a highly significant increase in the serum amylase level $(\mathrm{P}<0.01)$. However, this increase of serum amylase became significant when L-tryptophan was given in a dose of $250 \mathrm{mg} / \mathrm{kg}$ prior to LA. This observation was in accordance with the findings of Leja et al . (2004), who reported an improvement of serum amylase level when LT was administered prior to cerulein induced acute pancreatitis in albino rats. Administration of ALA in a dose of $50 \mathrm{mg} / \mathrm{kg}$ prior to $\mathrm{LA}$, in the present work also led to a significant $(\mathrm{P}<0.05)$ decrease in serum amylase level compared to control. This finding was consistent with that obtained by Park et al . ( 2005) who studied the effect of ALA prior to cholecystokinin (CCK) induced acute pancreatitis in albino rats.

In the present study, LA injection resulted in highly significant rise in serum IL-6 compared to control group. IL-6 is a pro-inflammatory cytokine, released in relation to tissue injury ( Park et al ., 2005).
The decrease of IL-6 in case of giving LT and ALA prior to LA was more significant . This was clearly evidenced by histopathological results which were revealed in LA group, excessive distortion of pancreatic acini, massive interstitial edema, vascular congestion, cellular infiltration, acinar cell necrosis and vacuolization of their cyto-plasm. These results are consistent with the results of Sledzinski et al . (1995) who reported that autopsies of the pancreas seen by light microscope, showed inter-stitial edema, acinar cell necrosis and vacuolization with leukocytes migration. Under electron microscope, Gul et al. (2006) reported swelling of the mitocho-ndria, disruption of mitochondrial cristae, as well as formation of large vacuoles arising from zymogen granules and liposo-me fusion. It was reported that in the earliest stages of acute pancreatitis , the inflammation is limited to the pancreas. Due to systemic action of diverse inflammatory mediators such as cytokines, reactive oxygen species ( ROS), proteolytic enzymes, lipids, etc; this locally limited inflammation quickly overspreads and develops into systemic inflammatory response syndrome ( SIRS) and eventually into multiple organ failure (MOF) which is responsible for pancreatitis associated mortality and morbidity ( Tamas et al ., 2005). The development of acute pancreatitis is considered as consisting of two phases: an early phase involving the activation of trypsinogen to the active protease trypsin and a secondary phase involving activation of the transcription factor nuclear KB ( NF- k B). Activation of this factor was found to be required for the production of chemokines by pancreatic acinar cells ( Han et al ., 2001) and endogenous inflammatory mediators, such as cytokines ( Grady et al ., 1997). These cytokines include interleukin-6, interleukin -8 , tumour necrosis factor- $\alpha$ and plateletactivating factor which are known to increase during AP ( Han and Logsdon, 1999). It was reported that acinar cells themselves express chemokines which 


\section{Lamia M. Farghaly et al}

attract and activate inflammatory cells. Early in the course of AP, there was an increase in the expression of mob-1, a member of the $\alpha$ - chemokine ( $\mathrm{C}-\mathrm{X}-\mathrm{C}$ ) family, and mcp-1, a member of the $\beta$ chemokine ( $\mathrm{C}-\mathrm{C}$ ) family in pancreatic acinar cells ( Han et al ., 2001).

Kishimoto et al. (1995) detected pancreatic oxygen free radicals ( OFRs) in AP using the technique of chemiluminescence probe and high sensitive photon counting and found that OFRs emerge 2$3 \mathrm{hr}$ after the induction of AP. When formation of OFRs overwhelms radical neutralization in cells, oxidative stress occurs. OFRs can attack polyunsaturated fatty acid's aldehyde group inside the biomembranes initiating lipid peroxidation and accordingly forming lipid peroxidation products, such as MDA which result in the loss of membrane stability and release acinar cell enzyme precursor. The released mediators activate phospholipase A1 which can decompose lecithinum inside cellular membrane, further causing tissue damage (Zhen et al ., 2006).

During ANP, activated neutrophiles are attached to endothelial cells, infiltrate into tissues, and produce large amount of reactive oxygen species and many cytokines, which may cause severe damage to the pancreatic tissue ( Jin et al., 2005).

Nitric oxide ( $\mathrm{NO}$ ), in addition to potent function of vasodilatation can also inhibit the adherence, infiltration and activation of white blood cells, and affect the production of reactive oxygen species. NO is generated by two classes of nitric oxide synthase NOS: one that is constitutive, $\mathrm{Ca}^{2+}$ dependent and physiologically activated (cNOS ) and the other is inducible ( iNOS). cNOS produces temperate amount of NO relieving ANP, whereas iNOS produces excess NO causes NO exacerbating the damage of ANP to the body ( Zhen et al ., 2006 ).

Another explanation for the toxicity of LA induced acute pancreatitis, is a NF$\mathrm{kB}$ which is a kind of plietropic regulative protein of transcription factor, belongs to the REL family and exists as a heterodimer or a homodimer formed by polypeptides P50 and P65. Its physiological activity relies mainly on the P50-P65 heterodimer, which exists in the cytoplasm of the majority of cell types at a high level. In the state of unactivation, NF-kB binds to its inhibitor $\mathrm{I}-\mathrm{kB}$ as an incompetence complex is "imprisoned' in cytoplasm and does not exert its function. In response to the extracellular stimuli, the activated protein kinase degrades $\mathrm{I}-\mathrm{kB}$ and then induces NF$\mathrm{kB}$ to separate from the NF-kB/I-kB complex. The free NF-kB translocates rapidly from cytoplasm to nuclei. In the nuclei, the NF-kB dimmer binds to its specific site-kB sequences and promotes the corresponding gene expression. Some could produce inflammatory mediators ( IL-6, TNF- $\alpha$, IL-1B, etc) and inversely augment the activation of NF-Kb to produce more inflammatory mediators and exacerbates inflammatory response ( Yongal, 2005). The results of the present study, revealed that LA group showed an increase in pancreatic Bax immunostaining. This immunohistochemical localization of Bax protein in the acinar cells agrees with Gomez et al. (2001), who revealed an increase in pancreatic mRNA and protein levels during AP. They reported that the AP-associated elevation in pancreatic Bax expression may be signalled partly by $\mathrm{p} 53$ since pancreatic p53mRNA levels are temporally coordinated with those of Bax.

The results of the present study provides the evidence that administration of melatonin precursor, L-tryptophan attenuates the previous histopathological changes provoked by $\mathrm{L}$-arginine overstimulation. These results were in agreement with Leja et al. (2004) who reported that Ltryptophan given (i.p) at high doses is able to protect effectively the pancreas from acute damage induced by cerulein. They reported that exogenous melatonin as well as that prod-uced exogenously from Ltryptophan protects pancreatic tissue from the acute damage by the reduction of ROS generation in the pancreas. It was reported that melatonin is a potent scavenger of ROS, and this indoleamine is able to scavenge the dangerous hydroxyl radical $(\mathrm{OH})$, which is produced in Fenton reaction ( Tan et al ., 1998). Since melatonin can easily cross the cell membranes, it was 
concluded that this indoleamine is able to pass through the blood-brain barrier and thus melatonin could regulate some processes in peripheral tissues ( Reiter, 1999). Besides melatonin's ability to scavenge ROS, this substance has been demonstrated to activate the antioxidative enzymes such as catalase and glutathione peroxidase (Watanabe et al., 2002). Previous studies have confirmed that content of lipid peroxidation in the pancreas is dramatically enhanced by acute pancreatitis caused by LA overstimulation or ischemia reperfusion (Jaworek et al., 2002). Administration of LT resulted in significant and dose dependent reduction of malondialdehyde (MDA) and 4- hydroxyalkens ( 4-HAE), the products of lipid peroxidation possibly caused by ROS in the pancreas subjected to I/R (Jaworek et al ., 2003). It was reported that acute pancreatitis is associated with increased expression and production of pro-inflammatory cytokines, such as TNF- $\alpha$, IL-1B or IL-6 (Jaworek et al ., 2003). So, some researchers demonstrated that administration of melatonin or L-tryptophan before the onset of CIP caused a significant reduction in plasma level of TNF- $\alpha$ while increasing that of anti-inflammatory cytokines. They also demonstrated that melatonin has increased gene expression and production of IL-2, IL6 and IL-12 while decreasing plasma level of IL-10 ( Leja et al., 2004)

However, the rats which received ALA prior to LA showed sings of protection against LA-induced acinar cell damage. There was some hemorrhage, mild edema and less necrosis compared to LA group. These results are in consistent with Park et al . ( 2005) who reported that ALA has a powerful antioxidant effect against cholecystokinin-induced acute pancreatitis in rats. Alpa-lipoic acid is a potent antioxidant that works with nutrients such as vitamins $\mathrm{C}$ and $\mathrm{E}$ and glutathione to defend against excessive free radicals. It is called a universal antioxidant because it is soluble in both water and lipid based tissue ( Packer et al ., 1995). According to Podda et al . ( 2001) and Goralska et al . ( 2001) ALA which is an essential cofactor in mitochondrial dehydrogenase reaction, has recently been shown to be a powerful antioxidant in vitro as well as being capable of regenerating vitamin $\mathrm{E}$ in vitro. Matsugo et al. ( 1996), reported that dihydrolipoic acid is an efficient hydroxyl radical scavenger through the direct reaction of dihydrolipoic acid with hydroxyl radical. ALA admin-istration has been shown to be beneficial in a numbers of oxidative stress models such as ischemia-reperfusion injury, diabetes, cataract formation, HIV activation, neurodegeneration and radiation injury ( Lu C, LiuY, 2001). ALA is also an important component in the energy product process within cells. In recent research, $600 \mathrm{mg}$ of ALA daily was found to decrease plasma LDL oxidation (Anudha et al ., 2007). According to Schonheit et al. (1997) it has a unique antioxidant activity extends to both its oxidized form and the reduced form. Naturally the reduced form dihydr-olipoic acid ( DHLA) is more powerful than lipoic acid. The antioxidant activity of lipoic acid relates to scavenging reactive oxygen species and chelating metals, whereas DHLA can, in addition, regenerate endogenous antioxidants such vitamin $\mathrm{C}, \mathrm{E}$, and glutathione and also repair oxidative damage. Recent study suggest that (Cyclooxygenase-2)Cox-2 inhibition by selective inhibitor ( SC58125), induced alteration of serum amylase and lipase level but not IL-6 and IL-1 production on caerulin (CAE) induced AP (Slogoff et al ., 2004). In the previous report, ALA markedly inhibited radiation or $\mathrm{H}_{2} \mathrm{O}_{2}$ - induced COX-2 upregulation (LiLi et al ., 2003). On the basis of this report, ALA may ameliorate AP via COX-2 inhibition.

\section{References}

1- Anudha G, Josephine A. and Varalakshmi P. ( 2007): Beneficial effect of DL: alpha-lipoic acid on cyclosporine A induced hyperlipidemic nephropathy in rats. Mol. Cell. Biochem. 16: 56-60.

2- Atmaca G. ( 2004): Antioxidant effects of sulfur-containing amino acids. Yonsei Med J; 45: 776-788.

3- Armitage A. and Berry G. ( 1994): Statistical Methods in Medical Research, $3^{\text {rd }}$ edn., Blackwell Scientific Publications. 
4- Bancroft J D. and Stevens A. ( 1990): Theory and Practice of Histological Techniques, Churchill Livingstone, $3^{\text {rd }}$ edn.,73-150.

5- Banks P A. ( 1993): Medical management of acute pancreatitis and complications. The pancreas: Biology, Pathobiology and Disease. New York. 593-611.

6- Baron T H. and Morgan D G. ( 1999): Acute necrotizing pancreatitis. $\mathrm{N}$ Engl J Med; 340: 1412-1417.

7- Beglinger C. (1999): Potential role of cholecystokinin in the development of acute pancreatitis. Digestion; 60:61-63.

8- Drury R A B. and Wallington E A. ( 1980 ): Carleton's Histological Technique. Oxford Univ. Press, New York, Tronto.

9- Gomez G, Heung M L, Qin H. and Ella W. ( 2001): Acute pancreatitis signals, activation of apoptosis-associated and survival genes in mice. Exper. Bio. and Medicine; 226: 692-700.

10- Goralska M, Dackor R, Holley B. and McGahan M C. (2001): Alpha lipoic acid changes iron uptake and storage in lens epithelial cells. Exp. Eye. Res., 76 (2):241248.

11- Grady T S, Ernst P, Liang and Logsdon C D.(1997): Chemokine gene expression in rat pancreatic acinar cells is an early event associated with secretagogue-induced acute pancreatitis. Gastroenterology, 113: 19661975.

12- Gul M, Ate B. and Yilama Z I. ( 2006): Ultrastructural clues for the protective effect of ascorbic acid and $\mathrm{N}$-acetylcystein against oxidative damage in cerulein- induced pancreatitis. Pancreatology, 6: 477-485.

13- Han B. and Logsdon C D. ( 1999): Cholecystokinin induction of mob-1 chemokine expression in pancreatic acinar cells requires NF-kB activation. Am. J. Physiol. Cell. Physiol. 277: C74- C82.

14- Han B, Baoan J. and Logsdon C D. (2001): Cholecystokinin independently activates intracellular trypsinogen and NF$\mathrm{kB}$ in rat pancreatic acinar cells. Am. J. Physiol Cell. Physiol., 280: C465-472.

15- Hirno T, Akira S, Taga T. and Kishimoto T. ( 1990): Biological and clinical aspect of interlukin-6. Immunol Today; 11: 443-449.

16- Jaworek J, Bonior J. and Tomaszewska R.( 2001): Involvement of cyclooxygenasederived prostaglandin $E_{2}$ and nitric oxide in the protection of rat pancreas afforded by low dose of lipopolysaccharides. J. Physiol. Pharmacol., 52:107- 126.
17- Jaworek J, Konturek S, J. and Leja S, A. ( 2002): Role of endogenous melatonin and its $\mathrm{MT}_{2}$ receptor in the modulation of cerulein-induced pancreatitis in the rat. J. Physiol. Pharmacol; 53 (4): 791-804.

18- Jaworek J, Leja S A. and Bonior J. ( 2003): Protective effect of melatonin and its precursor L-tryptophan on acute pancreatitis induced by cerulein overstimulation or ischemia/reperfusion. J. Pineal. Res., 34(1):40-52.

19- Jin L, Song N, Ping X. and Ren X G. (2005): Nuclear factor- kappa B activation on the reactive oxygen species in acute necrotizing pancreatitis. World. J. Gastroenterol., 11(27):4277-4280.

20- Kishimoto W, Nakao A, Inaba H. and Takagi H. ( 1995): Detection of superoxide free radicals in rats with acute pancreatitis. Pancreas; 11: 122-126.

21- Leja S, Jaworek J, Nawrot K. and Pawl K. ( 2004): Melatonin precursor, Ltryptophan protects the pancreas from development of acute pancreatitis through the central site of action. J . Physiol. Pharmacol. 55; ( 1): 239-254.

22- Li L, Steinauer K K; Dirks A J, Husbsck B. and Gibbs - ( 2003): Radiationinduced cyclooxygenase 2 upregulation is dependent on redox status in prostate cancer cells. Radiat. Res; 160:617621.

23- Lu C. and Liu Y. ( 2001): Interactions of lipoic acid radical cations with vitamins $\mathrm{C}$ and $\mathrm{E}$ analogue and hydroxycin-namic acid derivatives. Arch. Biomed Biophys1; 406(1): 78-84.

24- Matsugo S, Han D, Tritschler H J. and Packer L. ( 1996): Decomposition of alpha-lipoic acid derivatives by photoirradiation-formation of dihydrolipoic acid from alpha-lipoic acid. Biochem. Mol. Biol. Int., 38 (1):51-59.

25- Mizunuma T, Kawamura S. and Kishino Y. (1984): Effects of injecting excess arginine on rat pancreas. J. Nutr

26- Packer L, Witt E H. and Tritschler $H$. J. ( 1995): Alpha-Lipoic acid as a biological antioxidant. Free. Radic. Biol. Med.19; ( 2):227-250.

27- Park S J, Seo S W. and Choi O S. ( 2005): Alpha-Lipoic acid protects against cholecystokinin-induced acute pancreatitis in rats. World J. Gastroenterol., 21: 48834885.

28- Peter H, Zoltan R, Reka S, Csata G. and Lonovics J ( 2004): L-arginineinduced experimental acute pancreatitis. 
World J. Gastroenterol. 15; 10 ( 14): 30033009.

29- Podda M, Zollner T M, Packer L. and Kaufmann R.( 2001): Activity of alphalipoic acid in the protection against oxidative stress in skin Curr. Prbl. Dermatol., 29: 43.

30- Reiter R J.( 1999): The oxidant/ antioxidant network: role of melatonin. Biol. Signals. Recept., 8: 53-63.

31- Schonheit K, Gille L. and Nohl $\mathbf{H}$. (1997): Effect of alph-lipoic acid and dihydrolipoic acid on ischemia/reperfusion injury of the heart and heart mitochondria. Biochem. Biophys. Acta., 1271 ( 2-3): 335342.

32- Sledzinski Z, Wozniak M, Greci L. and Wajda Z. ( 1995): Protective effect of 4hydroxy- TEMPO, a low molecular weight of superoxide dismutase mimic, on free radical toxicity in experimental pancreatitis. Int. J. Pancreatol., 18 ( 2): 153-160.

33- Slogoff M I, Ethridge R T, Rajaraman S. and Evers B M. ( 2004): COX-2 inhibition results in alterations in nuclear factor ( NF)- kappa B activation but not cytokine production in acute pancreatitis. J.Gastriointest. Surg., 8:511-519.

34- Smotkin J. and Tenner S. ( 2002): Laboratory diagnostic tests in acute pancreatitis. J. Clin. Gastroenterol., 34: 459-462.
35- Tamas L, Csaba S. and Botond $P$. (2005): A nuclear import inhibitory peptide ameliorates the severity of cholecystokinininduced acute pancreatitis. World. J. Gastroenterol. 11 (17): 990- 999.

36- Tan D X, Manchester L C. and Reiter R J. ( 1998) : A novel melatonin metabolite, cyclic 3- hydroxymelatonin: a biomarker of in vivo hydroxyl radical generation. Biochem. Biophys. Res. Commun., 253: 614-620.

37- Watanabe S, Togashi S, Takakashi N.and Fukui T. ( 2002): L-tryptophan as an antioxidant in human placenta extract. J. Nutr. Sci.Vitminol; 48(1):36-39.

38- Winn-Deen E S, David H, Sigler G. and Chavez R. ( 1988): Kinetic determination of $\alpha$ - amylase activity. Clin. Chem; 34: 2005-2009.

39- Yong M, Qing Y M, Xiao P K. and Jun $X$ U. (2005): Effect of resveratrol on activation of nuclear factor kappa- B and inflammatory factors in rat model of acute pancreatitis. World. J. Gastroenterol. 28; 11 (4): 525-528.

40- Zhen-Dong Li, Qing Y, M. and Chang A W. (2006): Effect of resveratrol on pancreatic oxygen free radicals in rats with severe acute pancreatitis. World. J. Gastroenterol. 12( 1):137-140

\section{مقارنة بين التأثير الوقائى للتربتوفان- ال و حض ألفا ليبويك ضد ال- أرجينين}




\title{
المحدث للالتهاب البنكرياس الحاد فى الجرذان البيضاء
}

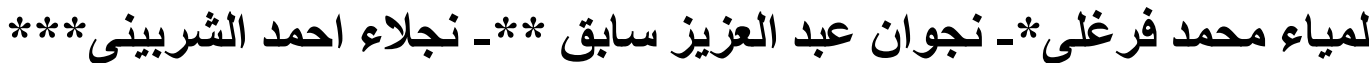

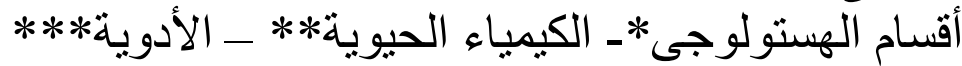

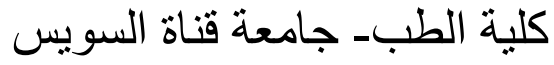

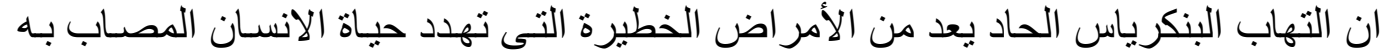

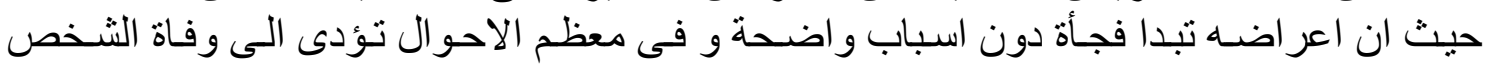

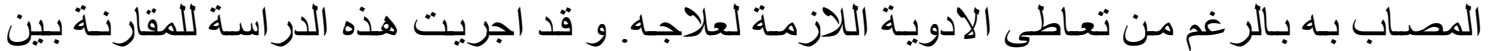

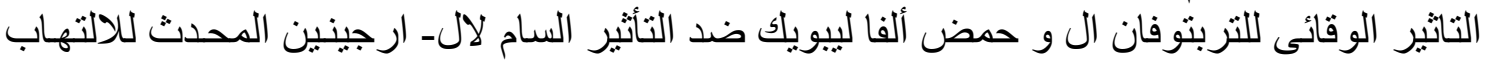

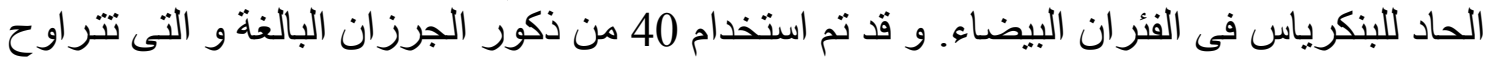

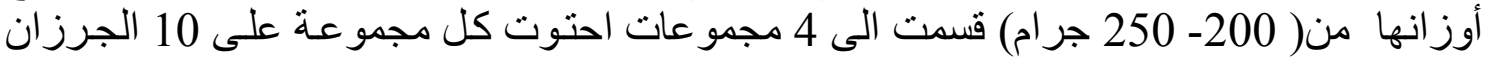

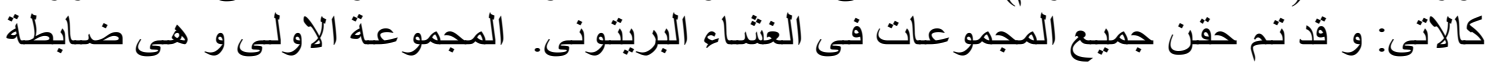

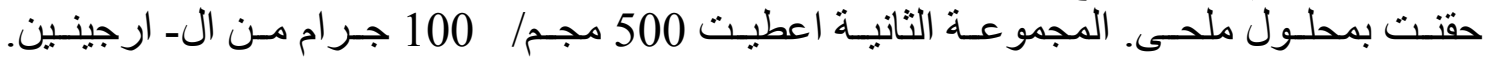

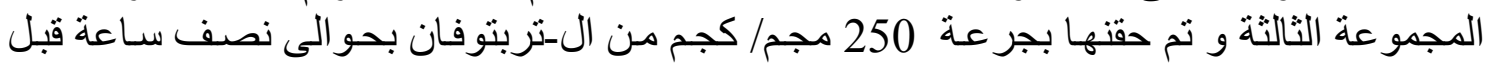

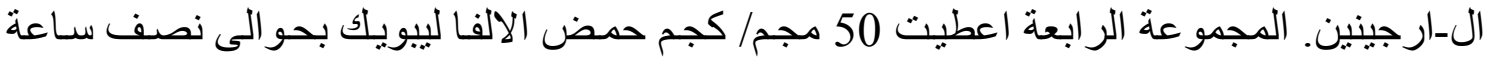

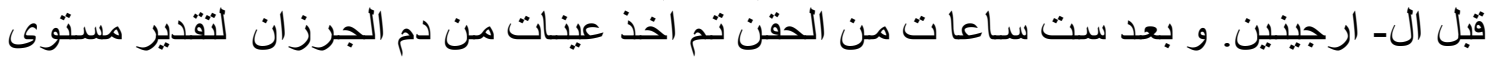

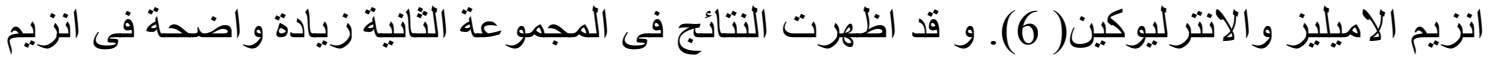

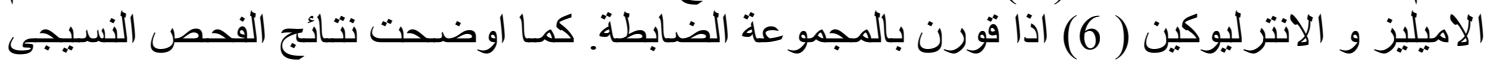

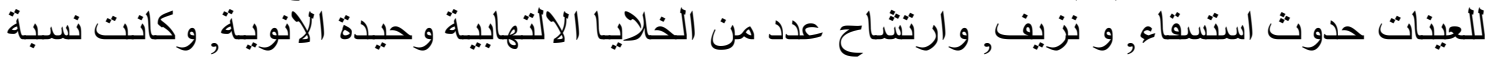

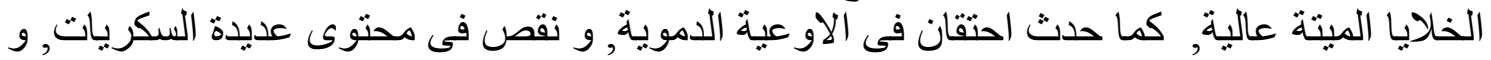

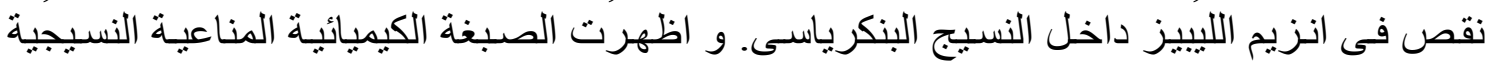

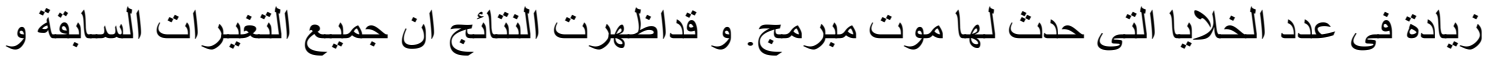

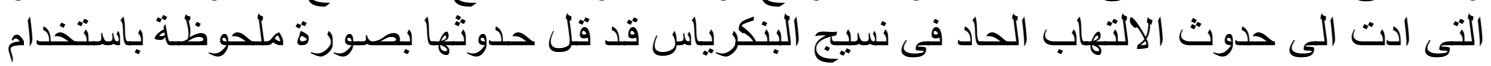

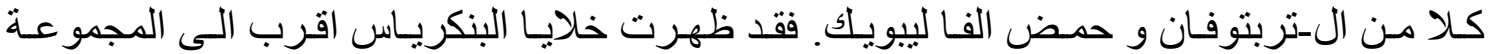

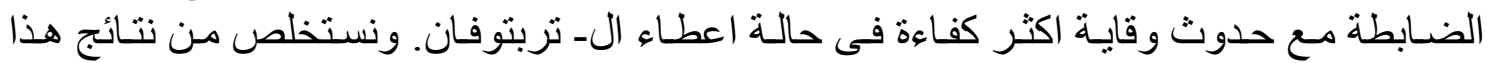

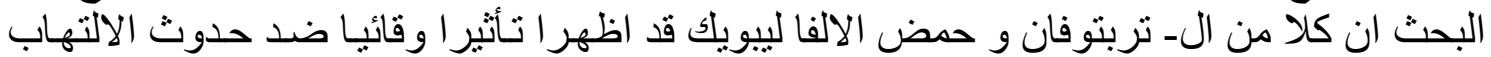

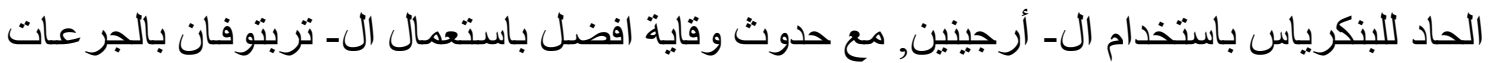

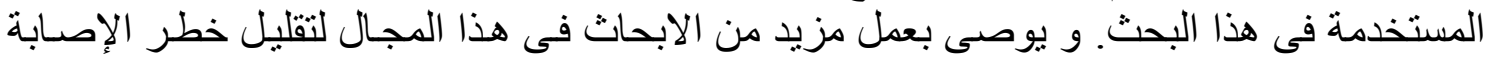
بالتهاب البنكرياس الحاد. 